\title{
CAPITALISMO, CULPA Y REDENCIÓN. (SOBRE LA FUNDACIÓN ESPIRITUAL DE LA METRO-POLIS)
}

Camilo Alfonso Salazar Flórez 


\title{
CAPITALISMO, CULPA Y REDENCIÓN. (SOBRE LA FUNDACIÓN ESPIRITUAL DE LA METRO-POLIS)*
}

\begin{abstract}
Resumen: El artículo expone una crítica a la llamada 'memoria histórica'. La actividad de recordar a los 'olvidados' se ha postulado como una actividad anti-capitalista por antonomasia. Por el olvido de sus 'orígenes' al habitante de las ciudades se le acusa de inautenticidad. Un análisis conceptual de las subjetividades en disputa hace notar que su oposición es solo aparente: ambas conforman la unidad formal del capitalismo. El sujeto que convoca a sus 'ancestros' y el que no cesa de moverse (capital) son ahora la forma de un mismo sujeto. Tanto la ciudad tradicional, que relacionaremos con la acción del recordar (determinabilidad), como la cosmo-polis, relacionada con los procesos capitalistas de límites erosionados (la ciudad que descansa sobre ella misma), son ya insostenibles. Es la Metro-polis (y sus criaturas), la que en su metraje se desborda, aquella que puede conjugar ambos momentos. Así que lo que se presentaba como resistencia al capitalismo, se hace notar como perteneciéndole de manera íntima.
\end{abstract}

Palabras clave: resistencia, memoria, tradición capitalismo, ciudad.

\section{CAPITALISM, GUILT AND REDEMPTION. (ABOUT THE SPIRITUAL FOUNDATION OF THE METRO-POLIS)}

\begin{abstract}
This paper exposes a critic to the called 'historical memory'. The activity of recalling the 'forgettable' has been postulated as an anti-capitalist action meant by itself. Because his 'origins' oblivion, the city's inhabitant is accused of lacking authenticity. However, a conceptual analysis of these subjectivities in dispute notices that their opposition is only apparent: they both are part of the new formal unit of capitalism. The subject, who convene his 'ancestors', and the one who is constantly moving (capital) are now the form of a same subject. Both the traditional city, which we will relate to the action of recalling (from being determined), and the cosmo-polis, related to the capitalist processes of eroded limits (the city that rests on itself), are no longer sustainable. It is the Metro-polis (and its creatures), which overflows his footage, which can conjugate both moments: Then, what was presented as a resistance against capitalism is also seen as belonging to it in an intimate way.
\end{abstract}

Keywords: Resistance, memory, tradition, capitalism, city.

Fecha de recepción: junio 26 de 2015

Fecha de aceptación: septiembre 28 de 2015

Forma de citar: Salazar, C. (2015). "Capitalismo, culpa y redención. (Sobre la fundación espiritual de la Metro-polis)". Revista Filosofía UIS. 15 (2). pp. 167-184.

Camilo Alfonso Salazar Flórez: colombiano. Magíster en Filosofía, Universidad JaverianaBogotá.

Correo electrónico: caalsaflo@gmail.com

\footnotetext{
* Documento de reflexión no derivado de investigación.
} 


\title{
CAPITALISMO, CULPA Y REDENCIÓN. (SOBRE LA FUNDACIÓN ESPIRITUAL DE LAS METRO-POLIS)
}

El Espíritu [...] es el individuo que es un mundo

(Hegel, 2006, p. 540).

\begin{abstract}
El capital exige una creación permanente de identidades subjetivas y territoriales para que su principio de movimiento homogenice su espacio de acción;

identidades, sin embargo, que nunca requieren nada más que el derecho de ser expuestas del mismo modo que otras

a las prerrogativas uniformes del mercado
\end{abstract}

(Badiou, 2010, p. 158).

Las ciudades y sus habitantes han comenzado a oír un llamado que se articula en un reclamo. Su acuoso cuerpo, se dice, necesita solidificarse, necesita tener un peso específico lo suficientemente considerable para no hundirse en la anemia histórica. Los dramas de calles y carreteras no tienen la suficiente temporalidad condensada para salvarles de un espacio omnívoro y autoproductivo. El drama agónico del ebrio baudeleriano que, cual infatigable Napoleón, lucha contra las paredes para no derrumbarlas ni derrumbarse, tiene solo la extensión de su cuerpo y de sus obsesiones. No basta que la ciudad se autosostenga obsesivamente para que persista, que la autoreferencia de su espacio generado sea la ostención suficiente que le alinea en el Ser. No le basta el azaroso deambular que conduce siempre a su misma figura. Ella debe ser sostenida, debe ser hija y ciudadana legítima. Lo que allí nace no es un cuerpo ebrio que tiene la certeza de un paisaje que le conforta y le calma (los humores negruzcos del alcohol bruman sus imaginerías). Pero, lo que nace allí, entre el afán de sostenerse desde y para sí misma y aquella 
tradición geográfico-cultural que podría sostenerle, es el Unigénito (Territorial) del capitalismo. Su forma adecuada, la cosa que ha dado a tientas con su concepto. Y lo ha hecho porque ha fabricado la (auto)'redención' desde una culpa que interfería con su movimiento. La ciudad 'despersonalizada' y el foco tradicional que querría funcionar como su origen conforman la metro-polis.

La fundación (de la ciudad), a partir de la tradición, tiene la forma de una persistencia de identidad que se relaciona con unas prácticas (llamadas) ancestrales. Prácticas que se refieren usualmente a los primeros habitantes conocidos y establecidos en un territorio determinado. No se trata de que un conjunto de prácticas (socio-económicas) se mantenga estable durante el proceso histórico de la relación ${ }^{1}$. Se trata de que aquellas prácticas generan una matriz, generan una forma en la cual la materialidad del proceso histórico de esa región particular se presenta: generan una estructura. Dicho mundo/materialidad se relacionaría con ese otro lugar que es signado por esas prácticas-objetos, y en tal relación el mundo se llena de un sentido propio de esas prácticas. Si esas prácticas donan una forma de lidiar con el mundo, ellas se mantienen en esa su formalidad (abstracción), se independizan del contenido específico que sustanciaba su racionalidad (Caillois, 1950, p. 12), y ellas mismas, en esa su independencia, adquieren, a su vez, como contenido su propia formalidad. Lo que las llena es el hecho mismo de ser esa estructura, lo que interesa es la presencia de una forma, cuyo origen es datable en un punto histórico determinado (pasado), en una fecha precisa. Lo que importa, pues, es la relación que esa estructura haría posible con un Otro asegurado (el pasado, que es él mismo dicha estructura) y asegurable, al alcance de la mano, y cuya presencia descentraría mi ser presente.

El hecho de estas formas puede estar vinculado con algún objeto-paradigma que condense la forma en general. Puede, por ejemplo, estar vinculado en nuestras regiones con la existencia del "mambeo" (tipo de mascado de hoja de coca). Pero la vinculación con dichos objetos específicos no indica la necesidad de que su entorno material haya sido igualmente heredado, de una práctica que se mantenga siendo la misma en el conjunto completo de creencias que le dan una razón de ser, aun si aparece como tal. Es decir, el objeto-paradigma (que puede ser igualmente una actividad aislada, tal como el llamado trueque, o el más generalizado Tarot, o un concepto como Pachamama), puede mantenerse aún si el espectro social que le hacía viable, y que le ubicaba en cierta racionalidad, ya no se mantiene ${ }^{2}$. El objeto se mantiene sin la materia misma en que él consistía,

\footnotetext{
${ }^{1}$ En un primer momento no es necesario que determinada práctica cargue la totalidad del sistema que le sostenía, sino que ella puede prescindir parcialmente de ese sistema. Así, la consideración de la ingesta del Yagé no implica la aseveración del entero edificio de creencias y prácticas cotidianas de las diversas tribus indígenas, donde este ritual cobró relevancia comunal. Basta que, en este caso, el Yagé sea datable en unas prácticas que pueden así denominarse ancestrales.

${ }^{2}$ Es decir, él mismo un objeto descentrado, ya no él mismo en tanto relacionado con ese
} 
ya que lo que interesa a este tipo de fundación es la posibilidad general de una relación 'deíctica' con lo ancestral y no con un 'objeto' literalmente heredado. No se trata de una herencia difusa y anclada en la muerte, apuntando como tesoro a la posibilidad siempre continua de la Salvación, transmitida entre los intersticios culturales (Benjamin, 2008), tampoco se trata de un ejercicio de historicidad, pues ésta lleva aparejada la noción de destrucción productiva de la Tradición (Heidegger, 2006, p. 44 ss.). Se trata más bien de un retorno formal y, a la vez, material, al Origen, la inversión lineal de la flecha temporal y la postulación del Origen como un momento abstracto y por ello como un 'paraíso' recuperable.

La materialidad informe del presente citadino, por esa "carencia de forma", por esa fluidez, hace necesaria tal vinculación con el pasado (se supone), sin la cual ese presente se manifiesta como carencia, como inauténtico, o bien y en la misma línea, como desastre y destrucción. Esa tradición aparece en la llamada estructurada en y desde la Ciudad. Es decir, el objeto-paradigma que tiene el espectro brumoso de una práctica determinada y tradicional, y que puede donar al presente con esta misma determinabilidad de la cual él es representante notable, ha aparecido en la mediación interpelativa que se ha hecho a sí misma la dinámica del capital. Y tal "objeto" así llamado, que hallaba su racionalidad en cierto tipo específico de (socio-)mitología particular, puede dar al ser del presente la estabilidad de la determinidad (socio-)mitológica que él mismo recoge en su especificidad. El ser del pasado funciona como lastre, como asidero, para impedir el vaivén de un presente cuya consistencia, de esta manera, se considera falta de ser propio pr. $^{3}$.

Al ritmo de la ciudad, ritmo ebrio en su ser-presente, se le opone, así, el ritmo mesurado del recordar, de unidades discretas, que se detiene en la consideración/actualización del pasado del cual se supone heredero privilegiado (elemento necesario en la matriz supuesta). El presente anclado se diferencia del presente huidizo en tanto que sirve como punto constante de partida en la ecuación temporal del progreso.

En el retorno a los 'orígenes' habita una potencia temporal que dona al presente de cualidades de lo que puede considerarse, así se espera, un tiempo no subordinado a los procesos de destrucción capitalista. Un tiempo pleno es aquel en el cual la línea temporal deja de estar en función de las relaciones progresistas presente-futuro, y en cambio hace que la presencia del pasado modifique dichas relaciones (habría una tenue matriz de la cual harían parte). Un pasado como asidero sólido garantiza la quietud necesaria de un presente acuoso que puede

Otro ('capitalismo', 'logocentrismo', etc.) de una manera negativa. Él se halla ya en un mundo globalizado, su mundo ha sido ya roto. Ya no es él mismo el que se aparece, sino que aparece él en cuanto otro. Aparece ya no en 'su' mundo, sino en el Mundo del capital. 3 "Ser propio", "autenticidad", queda definida en esta matriz, a través de esa inscripción en lo que allí se denomina Tradición. 
dar paso a un futuro cronológicamente accesible. Así, el futuro logra controlarse (tangente de la predicción) y transita desde ser proyecto (Heidegger, 2006, p. 44) o acontecimiento (Žižek, 2012, p. 68), a ser elemento contable, magnitud. Si el progreso, en la ideología liberal-capitalista, es la relación del presente con el futuro en donde lo huidizo de aquel se equilibra en relación con las consecuencias que pueda generar (Rosenzweig, 1997, pp. 140-144), ubicando así su estabilidad en esa relación tensionante entre lo siendo y lo será (tensionante en cuanto el siendo se ve condicionado, a diferencia de la dirección opuesta de la flecha temporal, por un aún no, del cual el primero es su 'causa' que se ve también condicionada por su mismo 'efecto', en un tipo de remedo isocrónico (Heidegger, 1996, p.103) que iguala ambos tiempos en la contundencia de la accesibilidad y la densidad del ser-presente), en el tipo de pensamiento que aboga por lo ancestral, por oposición, y que quiso mostrarse como contracorriente al capitalismo progresista, se presenta éste, el progreso, con el ingrediente que faltaba al capitalismo y que le había fabricado un flanco de crítica: el pasado. Así que la consideración del pasado, en este tipo de análisis, no es una ruptura con la forma capitalista, sino un aseguramiento de la misma a partir de la inclusión de aquello que se le escapaba. El pasado presentándose funciona mediante la ejecución de una circularidad potenciante y concéntrica constante. En lugar de un extraño y difícil progreso de presente a futuro, siempre a punto de caer por la acuosidad persistente del primero y la múltiple presencia homogénea del segundo, esta postura aboga por un retorno al pasado para potenciar, en el aseguramiento ahora bidireccional de la densidad ontológica del presente, el movimiento continuo.

Una imagen quizás sirva para aclarar este proceso: las naves exploradoras del espacio no logran su cometido mediante un viaje lineal con el impulso adquirido inicialmente y ocasionales potenciaciones del mismo a lo largo del trayecto, mediante su propio mecanismo de impulso. Su triunfo se asegura porque se acercan a diversos planetas (para viajar tienen que caer en el quieto ser de los errantes), 'caen' en su órbita, se mueven alrededor/tangencialmente del mismo, pero sólo para ganar un nuevo impulso, adquirir más energía. De esta manera su viaje está asegurado. Aquello que quería presentarse como una oposición radical al vacío hombre capitalista, cuya estabilidad dependía de un futuro aún demasiado impreciso, de un presente apenas apresable, en tanto que en tal oposición era considerada la opuesta dirección del movimiento (y que por ello, y en oposición a la indeterminabilidad de tal "sujetidad" del capital", acudía a la presencia de la

\footnotetext{
"Sujetidad" se comprenderá en analogía a las estructuras trascendentales, es decir, aquello que viabiliza las subjetividades. Por ello, la expresión "sujetidad del capital" difiere ontológicamente de "subjetividad(es) del capital" en tanto que la primera es la estructura que hace viable la segunda, que abre su campo de acción, que le pre-existe tal como el "concepto" que viabiliza los datos puros de la intuición, a partir de los cuales se podrá ejecutar la labor conceptual propia (Devries, 2008). O como la estructura general de la Cosa que pre-existe a toda cosa, denominada por Kant dewider: aquello que está allí, oponiéndose a nosotros, pero que no es ella cosa, sino el horizonte de apertura de toda objetividad en el cual los objetos particulares aparecen al sujeto finito (Žižek, 2012, p. 151).
} 
determinidad estable de ciertos objetos-paradigma), se halla en proceso de asegurar ese mismo movimiento, de potenciarlo. Por esta razón, no es casual, como repite en diferentes escenarios Žižek, que el futuro del capitalismo no descanse en el 'vacío' americano, sino en culturas cerradamente tradicionales como la china.

La segunda posición (la que tiene oídos para oír), que se ubica como el foco opuesto a aquella de la determinación del objeto-paradigma, quiere asegurar la identidad de la ciudad y sus habitantes pero a través de un movimiento diferente, ex-céntrico, respecto del primero. Si la primera quería ganar esta identidadpresente con el recurso a la matriz de unas prácticas pasadas, esta segunda forma de la identidad puede fundarse mediante un tipo muy diferente (y paradójico) de proceso (aunque veremos cómo hay un eje que focaliza ambas): una fundación que ya no recurre a una manía deíctica exterior, como aquella de los objetosparadigmas tradicionales, sino que solo puede existir en el momento mismo de su generación (su ser consiste en la misma generación, en el generarse mismo, en la 'autodeixis' generativa). Esta es autorreferencial, interna. Aquella es externa y reactiva ${ }^{5}$. La forma productiva que coordina esta fundación, el capitalismo, es, al menos lo que tal forma es sin su desarrollo extendido, el posicionamiento de relaciones productivas mediante la apropiación entera de las formas por ella usurpada. La forma de aferrarse a las tradiciones/mitologías particulares, permite la construcción de una unidad lo suficientemente cerrada y resistente, que permita evitar el embate triunfante de un movimiento productivo mundial, cuyo principio interno gira alrededor de la posibilidad de desolar todo lugar idiosincráticamente determinado donde logre establecerse con suficiente autonomía. Por eso el sujeto capitalista, no hablamos del mero negociante sino del sujeto como de la estructura de la sujetidad que conforma las subjetividades en esta Figura, un Mundo Espiritual, es cada vez más un sujeto 'libre' de sus filiaciones particulares, cada vez más indiferente a los habitantes ancestrales de su territorio, de movimientos inapresables, menos ansioso por una relación con sus orígenes geográfico-cultu(r) ales: no necesita ya de ellos pues él, su presencia autónoma, es su destrucción misma y en esta misma nadificación se presenta como figura apropiada. Puede decir soberana y sarcásticamente a la consciencia idiosincrática que esgrime sus derechos determinados:

Conocemos los lugares comunes que se pueden utilizar en este punto y que muestran siempre la misma cosa: no hay que luchar contra los poderes establecidos, no hay que luchar contra la fuerza, no hay que intentar elevarse por encima de la propia condición, toda acción que no se inserta en una tradición es un romanticismo, toda tentativa que no se apoya en una experiencia probada está condenada al fracaso; y la experiencia muestra que los hombres tienden siempre hacia lo bajo, que se necesitan cuerpos sólidos para dominarlos; si no, es la anarquía (Sartre, 2009, p. 24).

\footnotetext{
${ }^{5}$ No en cuanto ella en sí misma, como Pólis, sino ella en cuanto respondiendo a la actualidad. La forma de la fundación de la Pólis aparece por un llamado espectral que a ella trae a escena. Como tal, en sí, la Comunidad Tradicional no se funda como reacción.
} 
Cuerpos plenos de posibilidad, traslúcidos de mundos posibles, palabracarne cuya hondura se ha hecho escalofrío liminal. Presencia autónoma vaciada y multiplicidad destruida, o unidad desapareciente de lo múltiple y multiplicidad unificada en su grado cero, este es su mito más propio (hasta ahora).

La lógica interna del capitalismo le impulsa a la desolación territorial de las comunidades establecidas, en una suerte de continuo Destino Manifiesto que permita el despliegue histórico de su concepto (Žižek, 2012, p.241). 'Destino' que replica el sujeto, y es réplica del sujeto, que destruye todo lugar simbólico que no haya sido adecuadamente sancionado por sí mismo. Esa dinámica suya de autoproducción absoluta en el desalojo de toda alteridad, de toda solidez, le permite la desvinculación de todo fin: él ya no debe justificar su movimiento por la idea rectora de una 'vida buena', ni justifica su acción por un incremento de la felicidad (Han, 2014, pp. 33-40). Su único destino es él mismo, su autoproducción, nacer cada vez él (Žižek, 2012, p. 245). El sujeto de este presente de amplitud agónica, es un sujeto desolado en el cual el flujo de capital puede igualmente no tener fricción alguna para la consecución de su objetivo: su autogestación constante (la 'macro' y 'micro' estructura deben corresponderse para un movimiento sin fricción, para que pueda aparecer el "frictionless capitalism" (245)). El tiempo (aquello mismo que somos) se estructura en la figura de una progresión geométrica, el tiempo es la estructura de esta multiplicación, que no aumenta el territorio suyo pero es la forma de toda amplitud. El alma, que es tiempo, y el tiempo es dinero, como lo hizo notable Benjamin Franklin en su célebre Advice to a young tradesman:

\begin{abstract}
Remember that Time is money [...] Remember that Money is of a prolific generating Nature. Money can beget Money, and its Offspring can beget more, and so on. Five Shillings turn'd, is Six: Turn'd again, 'tis Seven and Three Pence; and so on 'til it becomes an Hundred Pound. The more there is of it, the more it produces every Turning, so that the Profits rise quicker and quicker. He that kills a breeding Sow, destroys all her Offspring to the thousandth Generation (Franklin, 2004, p. 200).
\end{abstract}

Al tratarse de la movilidad pura, ningún tipo de ente denso tiene cabida en su trayecto general y específico; no hay 'pasado' más que como material de la aniquilación; el "descendiente" es él mismo Padre inmediato, trans-Género. Nuestra estructura básica, el tiempo, se configura como producción constante y nula. Constante en cuanto todo momento genera a otro. Nula en tanto que el tiempo no es más que esa necesidad de producción, tal como el dinero no tiene como fin más que la producción de más dinero. El objetivo final no anida en un objeto o estado ideal, sino que yace en esa autorreferencia productiva: se produce dinero para producir dinero, tanto como un momento se explica en su ser tránsito para otro. No debe haber nada que interrumpa el flujo de deseos de esta máquina excrementicia. Ni traumas. Ni vergüenzas. Ni ascos. Debe poder contemplar en 
el reflejo del mundo, la figura desatada de su interior. Todo debe fluir. Cada uno de los momentos es cada uno de todos los otros, se mueve de Género en Género, siendo cada instante un Género pleno y siendo todos los instantes.

Por su parte, el mundo tradicional "está marcado por límites, cruces y umbrales, por vallas, zanjas y muros. Estos impiden el proceso de cambio e intercambio universal" (Han, 2012, p. 16). Límites que entonces quieren corroerse, cuya desaparición se hace necesaria. Así que la "patria" para este sujeto hijo-padre, es un impedimento, o quizás solo el errante lugar a donde siempre se regresa después de los viajes; el amor binario vinculante, (auto)destructivo y patológico (que detiene el movimiento al depender y coexistir patológicamente con otro) (Kristeva, 2006) es 'desmitificado' para dar paso a lo que se denomina poliamor', en donde cada vínculo emocional se difumina en la numeraria presencia de múltiples cuerpos (el vínculo válido es con sí mismo, y todo otro vínculo conduce siempre a esta mismidad, todo Otro no es más que escala 'ocasional' al encuentro positivo con sí-mismo); la defensa que la mujer fabrica en esta sujetidad en busca de una identidad que se había puesto en duda por el sistema imperante, se basa usualmente en la policefálica y homogénea performatividad de tautologías fundacionales como "mi cuerpo es mío", en donde la autorreferencialidad de dichas acciones permitirían la determinación del espacio propio y el desanclarse, de dicho nuevo espacio, de dicha mujer, de todo rol social heredado (opresor), que no ha sido adecuadamente asegurado por su misma autoconsciencia (debe ganar un cuerpo que ha sido siempre puesto en duda, que siempre había sido hipotecado a Otro (Roudinesco, 2006), y ello se lo permitiría la forma circular de tal expresión, allí se determina una figura, se logra establecer la mismidad de un territorio naciente): ella es un constante para-sí desencajado de su paraotro (al menos en su posición primaria), pero esa misma forma de su fundación tautológica se apresura en un cartesianismo apremiante para la recuperación de un cuerpo apenas naciente (la res extensa es precedida por la Voz que le llama), y la construcción de esa libertad muestra la paradoja de un acceso mimético respecto a las instancias mismas que habían servido a su opresión: la especificidad de lo femenino que abría su búsqueda, aun siendo ella misma opaca en ese momento iniciático como lo es todo momento de apertura, se diluye ante la presuposición clara de la respuesta que la misma apertura habilita: aquel Yo-pienso es la estructura misma a la que se dirige ya, es la pre-comprensión ya ratificada en su opacidad, la posibilidad del puro movimiento cuyo límite no es más que un sí-mismo desbordado (corolario de ello es la limpieza de la diferencia sexual, el desbordamiento del género específico en la intersexualidad, o la ausencia de toda necesidad de determinación sexual, como idea rectora, y así aquello específico que abrió la búsqueda debe elidirse a sí mismo para a sí mismo encontrarse: la mujer desaparece en la fluidez naciente; condenada por demasiado tiempo

\footnotetext{
${ }^{6} \mathrm{O}$ en una versión diferente, ese mismo amor es reducido a ser componente biológico, interacción de encimas, y así epifenómeno neuronal o bio-químico.
} 
a ser Madre, Prostituta o compañera 'servicial', perseguida innumerables veces por Bruja, compañera de Satanás, exaltada hasta el delirio del fuego y la horca (Michelete, 2014), ella misma hace estallar todo género, encontrar su lugar hace que necesariamente todo lugar sea puesto en duda, ella misma quiere redefinir el espacio en donde se le había puesto, y así redefinir el Espacio mismo, reconstruir la geometría entera del universo humano es su labor más grande y vital, pero en tal redefinición parece repetir el gesto trágico de toda fundación (Benjamin, 2010), se ve atrapada en el gesto de aquellos mismos que le habían postulado el horizonte de su propia comprensibilidad, cae presa de la furia de un yo-pienso que ahora se sabe libre e infinito en la posibilidad de su negatividad, en el amanecer en su vocabulario del "no" (Roudinesco, 2006, p. 159-165) y con ella entonces quiere incendiar el Mundo, y ella, a pesar de sí misma, en su excepcionalidad respecto al discurso del Padre, halla su mismidad en aquello que continua situándose como la instancia de opresión, aparece como el remedo (la excepción) de los que habían sido sus Patrones ${ }^{7}$.

Todo proceso de desvinculación (con las continuas atenuaciones que sus teóricos le presentan) parece funcionar bajo un gran y difuso sentimiento: un tipo de temor al cuerpo mismo. Horror al cuerpo, a las determinaciones "excesivas" que se muestran en la figura determinada-finita de esta carne manchada de temores, vicios, prejuicios etc. y que alcanzan su difuminación en el estilizado cuerpo cibernético. ¿No es acaso la 'ironización' de todo esencialismo la necesidad de perder esta determinación que es el cuerpo en su densa mismidad, su determinación epidérmica? ¿No es este horror a la determinación lo que impulsó al padre Surin a desfigurar su cuerpo a través de castigos y lo que mueve a Orlan en sus recurrentes performances? Horror al pre-juicio, a la creencia 'dogmática', a la fijeza, que regresará en la forma despiadada de violencia religiosa... El capitalismo, como flujo constante, huye y debe huir de la determinación. El cuerpo encarnado del pecado de lo finito, de olorosa carnalidad, le horroriza, aun cuando sea del cuerpo de lo que más allí se hable (pareciere que el multitudinario discurso sobre el cuerpo en el presente quisiera acallar el terrible lugar que allí ocupa). Horror a la carne misma en su inevitable determinación, al placer mismo que consume, que abre y muestra las formas internas de la carne, su abismo: el vicioso es aquel cuyo yo-pienso es apenas estertor yonqui, que se consume en las llagas de su placer, en cuyos pliegues aparece el obsceno secreto del Mundo. Putrefacción es su carne ensimismada, desalojada del secreto del Goce "ordenado" del libertino, de la estética del placer. Cuerpo denso y exhausto en su estatuto de mismidad bovina, incapaz de gobernar su vida mediante las pautas necesarias que potencien

\footnotetext{
${ }^{7}$ Las críticas acá esbozadas no pertenecen a la longitud de nuestro escrito, pero se deja sentada su presencia por tratarse de los habitantes de la ciudad: aquellos que hablan y a quienes se habla, aquellos a quienes se acusa. A la crítica de este tipo de feminismo, el que se ha alineado con los poderes dominantes mientras se proclama contra los mismos, Weininger, en su único y profético texto "Sexo y carácter", supo notar esta paradoja de manera más profunda que muchos autores.
} 
su goce, que detengan el ánimo de ser consumido y nazca el correlato necesario del consumir. Carnes bovinas en proceso de ser cucarrón que antes del vuelo rehabilitan sus opciones constituyentes. El cuerpo del pecado del capitalismo es el cuerpo, el cuerpo de mil pliegues, que acoge en su geografía continentes de almas, contra él golpea y quiere redimir mediante los suplicios de la pura positividad, de la pura mismidad: no puede haber nada así como un echarse a perder, un podrirse; la carne debe agarrarse en su plena posibilidad, en su más pura mismidad y espulgar cada arruga liminal para sacarla a superficie y explotarla: nada bajo la sombra, todo en el sofocante mediodía; no puede haber olvido en los humores de los cuerpos bajos el sol, pues todo olvido es culpa, toda descomposición se asume como un proceso de recuperación para una 'superación' adecuada de ellos mismos, y así todo debe mantenerse (modificación de la aufgehoben), todo debe ser recordado, numerado, agendado, nominado, y dar paso así a la ciudad del metraje estipulado... Mas ese cuerpo no sufre mediante golpes o tratamientos definitivos, sufre porque no puede morir, porque se mantiene en el umbral de la muerte constante y numerada, desespera (Kierkegaard, 2004, pp. 28-29); no se le desmiembra porque es cuerpo ya desmembrado, no-cuerpo, o más bien es Órgano Puro, es división infinita en constantes transgresiones, perversiones, suplicio que gana la seguridad de su continuidad. Islotes que el Capital Unigenito utilizará en la figuración de su archipiélago. Mala consciencia inconsciente de un cuerpo que aún gime mediante una boca que ya no puede siquiera aparecer.

Es ante esta estructura de la subjetividad presente en el capitalismo, ante y frente a lo cual adquiere fuerza la estructura de la determinación 'tradicional': la densidad que ésta permite establece la no-disposición al vaciamiento de los componentes (tanto en el nivel Universal como en el nivel Individual) para el establecimiento primario de aquel orden económico. El cosmopolitismo, en sus diferentes versiones y esferas, es solo el siguiente paso 'lógico' a esa expropiación iniciada hace ya varios siglos (en la expropiación de/a los señores feudales, su desterritorialización), es la limpieza de toda particularidad que pueda impedir el flujo libre del capital, la eugenesia inversora. Desde los movimientos anarquistas del amanecer español, transitando por las costas californianas y sus experimentos comunales (Houellebecq, 2009), atravesando la reconfiguración de la familia, su 'horizontalización', hasta las actuales formas generales de modificación corporal y nuevas maneras de concepción humana (por ejemplo, Roudinesco, 2006), el movimiento del individuo hace reflejo del nuevo movimiento del capital que quiere apoderarse de todo el orbe. Su inconsciente se materializa en el bitcoin. Los particulares que son el objeto de consideración y defensa de este tipo de pensamiento se muestran como el mismo sujeto-nada, liberado de todo aquello que él mismo no sanciona como su ley, quiere "apropiarse" de su tradición, hacerla suya en el furor de su destrucción: Edipo ha vencido toda legislación, incluso la de sí mismo: en sus ojos arrancados, que veían el mundo como su mundo, solo puede ver la misma noche carnal de las cuencas de todos los hombres. La misma matriz de comportamientos se ejecuta en ellos, y la diferencia, 
la propiedad anhelada en el discurso hegemónico, en su exacerbada y maniática presentación, finaliza en la lógica de la identidad absoluta, entendida como la lógica de la identidad mecánica (Lear, 1990, pp. 121-125). No hay un otro al que oponerse, nada es externo a ellos pues no hay nada suficientemente denso como para presentarse de esta manera (que será ellos mismos). La otredad se diluye en la diferencia general, y hace presencia allí la política de la 'simpatía' (Zuleta, 1985, p.116). “A la diferencia le falta, por decirlo así, el aguijón de la extrañeza" (Han, 2012, p. 14). Todos son la misma nada polivalente, el curso alegadamente infinito de la energía. La particularidad de la materia, sus avatares azarosos y pesares coordinados, se convierten en el haz igualitario de la energía, del movimiento. Tal como en el capitalismo mundial se desuelan territorios autóctonos para la territorialización particularmente homogénea, el sujeto del capitalismo pierde su identidad 'autóctona', pero mantiene la identidad de matriz que da lugar a la pluralidad inabordable de vidas que, sin embargo, mantienen su Absoluta identidad. La identidad de las comunidades autóctonas de los territorios delimitados, se convierte en la identidad (de matriz) absoluta de los individuos del mundo globalizado del libre mercado. De modo que ella, la matriz como determinación, nunca había desaparecido, y el nacimiento determinado de lo global aparecía como su forma más propia en esa matriz, pero también era el pecado contra el que continuamente tenía que luchar: en sí mismo reencontraba aquello que se suponía conjurado.

La identidad que se genera en este movimiento no requiere relación alguna con un cierto antepasado. Requiere, a lo sumo, la presencia (inevitable) del presente y la posibilidad de movimiento a través suyo hacia el futuro que es solo el futuro como accesibilidad, como mismidad en tal accesibilidad, (tal movimiento es lo que se había mencionado arriba como remedo isocrónico), movimiento fantasmático entre la nada movible del presente y la nada como loque-aún-no-ha-sido-y-ya-viene-siendo del futuro (Žižek, 2012). Si comprende el pasado es para arrojarlo en su vórtice. Inscribirle en una tradición, rastrear su gesto devorador en el gesto de una 'episteme' que le guía y le cerciora, es no comprender el funcionamiento interno de este nuevo hombre. No ha nacido de nadie, y ello no es desmentido por una deixis histórica. Tal gesto solo sirve para que él aumente el furor que le funda. Su ánimo de fuego quema toda huella. Es nacido de virgen, y ningún gesto puede inscribirlo en ninguna tradición. Ha nacido aquél que es viento y fuego. Ese mismo cosmopolitismo del furor apela a la posibilidad nueva de un pueblo emergente: un pueblo que solo se necesita a sí mismo (sí mismo heredado de la determinación de su origen 'tradicional') y a sus proyectos de aseguramiento autorreferencial. Pero él mismo ha engendrado al hermano que se le opone. Si aquel es viento y fuego, éste es tierra y agua, sedimento. En oposición, entonces, el 'origen' funciona como posibilidad de resistencia a una lógica destructiva, pues se supone vulgarmente que el origen, lo venido de/en el origen persiste (que el Objeto carga la socio-mitología que lo había fundado). Es decir, lo venido del 'origen' des-centra el ser puro presente 
del esto que ha 'venido' desde allí, y en el reconocimiento de ese lugar se funda entonces no únicamente a través de sí mismo sino a través de la relación con aquel origen. El peso del ser-presente del capital que se funda en la amplitud general de su automovimiento, disminuye cuando esa amplitud no se refiere al mismo campo sino que queda referida a aquél lugar. Pero esta estructura de este tipo de fundación municipal, aparece no independiente de aquella del capital autogestionante, sino como resistencia a aquella lógica: ella cumple ese traer a vida de este soberano sobre su muerte. Y ello mismo, esa misma resistencia, es lo que salva (en apariencia) al capital de la pura tautología. Crasis perfecta de los cuatro elementos. Si bien todo horizonte desaparece de él, todo fin le abandona, y queda él autoabsorbido en su mismidad, esta mismidad logra des-centrarse, y a partir de sí sacudir esa forma simple de infinito. Su constante autogestión (edípica) implica la presencia masiva de su mismidad. Pero ella misma en la desolación que la sostiene y en que ella consiste, logra, a través de esta desolación, hacer campo a la diferencia simple (que no al otro atópico (Han, 2014)). La diferencia que ella invoca, en tal mismidad, es la de aquello que desuela, aquello que ella ha consumido para ser lo Mismo. Lo desolado abre agujeros a la mismidad, pues no es parte homogénea de lo Mismo, o en otras palabras: ella solo es lo Otro en cuanto ha sido traída como Otro por lo Mismo. En tanto que en dicha acción ella misma se patentiza, y lo Mismo se hace a partir y en lo desolado, ese movimiento gana así la presencia estructural de lo diferente, que se convierte entonces en un movimiento (concéntrico) de su patencia. El capital que había perdido todo fin diferente a sí tiene un remedo teleológico en la diferencia de lo desolado: la sustancia agujereada solo es ella misma tal sustancia en ese mismo agujereamiento. Él, que no podía más que escucharse a sí mismo, por la forma extendida de su mismidad operante, ha abierto el campo para eso que no es (aún) él, pero que deberá serlo en la llenura, eso que él ya mismo ha "creado" y solo cobrará vigencia en el Reino. Ahora puede oír a los olvidados, a los que su movimiento había desolado, pues la claridad de su Ser hace campo a una (remedada) nubosidad. Así que si el fin de la 'vida buena y bella' ha salido de él para dar el campo al dominio de la pura inmanencia, el rodeo por la desolación permite recuperar, dentro de tal inmanencia pura, lo otro. Lo "otro" ha sido tomado por la espalda por lo Mismo, ya es parte suya, ya es estructura, aun en su presentación de radical diferencia, tiene presencia solo en la mediación de la mismidad. Aritmética de la desolación. Lo otro en cuanto Otro se postula como tal Otro en referencia (mediativa) a lo Mismo. El destino edípico del capitalismo ha logrado su cometido. Padre e hijo, abuelo y abuela, hermanos y hermanas... víctima y victimario, como nota constantemente una sabiduría transhistórica, vienen a ser un mismo ser: éste es el que oye los gritos que solo aquél dejaba salir en el dolor traído por éste. La presencia en el mismo escenario de ambas fuerzas, de la fuerza capitalista que cohesiona los territorios en su desolación desterritorializante y la resistencia a ella que desconfigura esa imagen nítida, permite la creación de un nuevo tipo de comunidad, no a un nuevo tipo de "fundación" (la estructura de la fundación permanece atada a los dos tipos de violencia, que son la misma: fundacional y de 
aseguramiento (Benjamin, 2010), no se apunta a una Violencia diferente, divina). Una comunidad de la convivencia parcial de los contrarios, pero de la existencia absoluta del todo: génesis del Unigénito.

Es la cosmo-polis, ciudad sin medidas, la que tiene oídos para oír. La resistencia que a ella se le presenta y le cuestiona, sobrevive en esta dialéctica como presencia en las llamadas 'reservas', o colectivos conservacionistas o de memoria histórica y reivindicativa, que permiten la continuación del movimiento. En estos casos la oposición, la resistencia, fue un elemento mismo del avance ${ }^{8}$, en tanto que le fortalece. El movimiento cargando ahora sin problema esa oposición, permitiendo la dislocación de su ser propio en sí mismo y para sí mismo, modifica su ser (su haber sido puro incremento de sí mismo), de la misma manera que la oposición deja su estado de alteridad y se hace parte esencial de tal movimiento ${ }^{9}$. Todo otro se consume en lo mismo, y este no es más que otro por venir. En la "sociedad del riesgo" toda comunidad, aun la más cerrada y protegida de ellas, se ve ya mediada por la presencia contundente de lo Mismo. El poder es una bestia (y soberano) que carga en sí mismo aquello que le resiste, de modo que no se trata de quien tiene el poder, sino de su ejercicio, es decir, del Movimiento Mismo, del cargar. Así, Foucault tiene, a pesar de sí mismo, una inesperada confirmación en esa relacionalidad: "Donde hay poder hay resistencia, y no obstante (precisamente por esto), ésta nunca está en posición de exterioridad respecto del poder. [...] Los puntos de resistencia están presentes en todas partes dentro de la red de poder" (Foucault, 2005 pp. 100-101). La resistencia, la perversión, el crimen, o como quiera llamarse, es solo para y por la Ley misma (Roudinesco, 2009; Bataille, 1992).

Si el capitalismo había triunfado, y sus criaturas se encargaban de mostrar tal triunfo en el ser-para-otro, su densidad (tanto material como conceptual) se veía siempre puesta en duda, rota, por la presencia de un "pasado" del cual él no podía hacerse cargo. La desolación que su movimiento traía sobre los pueblos establecidos, le hacía objeto de continuos 'reclamos' [¿Acaso sufría de mala consciencia? ¿Acaso su odio al cuerpo como determinación, como negación, aparecía ahora como una culpa que amenazaba sus pasos ante la evidencia de una inevitable determinación presente en su matriz difusa? ¿Acaso su origen religioso y determinado se hacía evidente en que aun poseía oídos para tal tipo de quejas? Aquello que le permitía oír era su sí mismo]. Los 'olvidados', aquellos que el movimiento había callado a la fuerza en la destrucción de su voz, se le hacían presentes en sus reclamos fantasmales rompiendo la densidad que el mismo capitalismo, en esta fase de autogestación extendida, requería. Requería numerar

\footnotetext{
${ }^{8} \mathrm{Y}$ es claro que esta humanización del capital, al ser este un mundo que 'funciona de esta manera' y ante el cual no se puede hacer nada, es todo un triunfo para algunos.

${ }^{9}$ En tanto incremento de sí y en tanto pausa en sí mismo, esta figura se relaciona especialmente con la teoría de Bataille de la producción y el gasto improductivo, expuesta en extenso y claramente en el texto "La parte maldita".
} 
de nuevo, devorar, pero con unas nuevas maneras. Mas esto solo hacía notar que el capitalismo no había llegado a su presentación más terminada, aún era en una pólis sin medida, desmedida, abismal. Su concepto era pura abstracción aún. La posibilidad misma de que aquellas voces aparecieran como fantasmas, no era una forma de dar de baja (deícticamente) dicho sistema. Pues el "otro" negado que tenía que aparecer no podía hacerlo más que bajo las condiciones de posibilidad del "esto". "El pasado ha de tomar los rasgos del presente. Solamente así será completamente inofensivo para éste" (Rosenzweig, 1997, p. 143). Para ser escuchado, el pasado (olvidado) debe aparecer bajo una estructura semántica que posibilite su misma voz, la interjección de la desolación se vuelve ella tal interjección en la medida en que hay alguien que le escuche (que es el problema mismo del origen del universo a partir de la soledad de Dios) y en la inmanencia pura solo el presente continuo puede ser tal estructura. No se trata, como suele pensarse, que deba regresarse a la conceptualización originaria de pueblos o comunidades autóctonas arrasadas en primer lugar, ya que ese gesto mismo del regreso ha sido abierto por su muerte iniciática. No hay posibilidad de regreso que no haya sido ya "prevista" en lo Mismo. Esa misma apertura en contra de este Padre, esa necesidad de encontrar un dialecto propio, diferenciado del Genitor, finaliza con un remedo inverso de esa figura. Lo contra-hegemónico, como lo dice su gramática superficial, se sitúa como una inversión de la hegemonía, como un nuevo espacio simbólico que descansa en la inversión del primero. Querer ser oído en propiedad, con un lenguaje que se quiere propio, postula un oyente que no me oía, un Padre que obstinaba en desaparecerme. El lenguaje atópico del pasado no tiene espacio en la premura del presente. El verdugo da lugar al lamento de su víctima; ésta le pertenece por completo a aquel, pues es él quien le hiere y quien oye su último estertor, en juego de seducciones recíprocas; él, por el contrario, se le escapa a ella (Hegel, 2006, pp. 286-301), y le queda el último recurso de un reclamo que conmueva a su Reino ${ }^{10}$. Su primera forma de aparición no fue en cuanto otredad determinada y precisa, como alteridad atópica que destruye ${ }^{11}$ la forma misma de tal estructura, sino en el hecho del oír: porque el otro debe aparecer, y debe aparecer porque la mismidad se ve ella agujereada y reclama la 'terapia', reclama llenura, porque el otro persiste pero aun es indeterminado, porque su persistir se ubica como función de lo Mismo, su ser otro fue la misma presencia de tal oír, el que se poseyera oídos para oír. El lenguaje "irracional" de lo otro, irracional en cuanto su especificidad sale del marco de la comprensibilidad establecido por la mismidad, se traducía en la plural tonalidad del lenguaje en la matriz del presente. Al ser oído el ser no sido del

\footnotetext{
${ }^{10}$ La labor del fantasma así entendido, de este tipo de concepto de fantasma, es deambular y traer ese mismo dolor, al cual fue sometido, a la luz del Reino: "Ay de mí, muero, sí, sí, maldito, muero, pero has de seguir temiendo mi venganza: incluso bajo tierra seguiré siendo tu enemigo acérrimo [...] Haré temblar tu trono, desasosegaré tu nupcial lecho, tu amor y tu contento, e infligiré con mi ira todo el daño posible al rey y al reino" (Stranitzky citado en Benjamin, 2006, p. 348).

${ }^{11}$ Cuya violencia se apropia del acto divino de su ser violencia, ubicándose en otra coordenada a la de la fundación binomial identificada por Benjamin (2010).
} 
otro se prestaba para ser reclamado por aquel que le oía. El fantasma reclamaba un cuerpo. Pero ya no el cuerpo de ese otro negado, ya que dicho cuerpo había sido elidido en el sacrificio, sino el otro en la claridad meridiana de lo Mismo: ya se ha implantado la soberanía semántica de su mismidad. La cosmo-polis había ya efectuado su trabajo, el trabajo de la pura desolación en tiempos continuos, y así el cuerpo que aparece es el cuerpo del "esto". La mala consciencia del capitalismo no era tan sólo pecado despreciado. Era el pecado que construía y prometía él mismo la "redención", la resurrección, la manera en que aquél podía acceder a reconocer el proceso en el cual aún debía inscribirse: a partir de la muerte que él mismo hace podía transitar al Nuevo Reino. Si bien había adquirido la forma de un progreso simple, ahora en el mea culpa que él mismo hace posible y que hace necesario, se nota la nueva forma, el nuevo cuerpo. El extremismo tautológico de sí mismo permitía la vaga modificación interior de sí. La interjección culpabilizante precedía al cuerpo del que ella ya era parte. Ya no solo se trata de agarrar por el cuello el presente y estrujarlo hacia el futuro, se trata de llegar a la hegemonía del tiempo entero, de sus tres conocidos estadios. De frenar momentáneamente el proceso de producción para que el mismo pueda tener lugar seguro (Agamben, 2011; Han, 2012). Solo cuando la mala consciencia se vuelve consciencia de sí y para sí, puede llegarle su adecuada presentación. Así cumple con su concepto, articulando el absoluto de su ser con la particularidad 'heterogénea'; así nace el mismo Todo, el Unigénito: “El todo es un equilibrio quiescente de todas las partes, y cada parte es un espíritu indígena, nativo, un espíritu centrado en lo suyo, que no busca su satisfacción más allá de sí mismo, sino que la tiene en sí mismo precisamente porque se encuentra en ese equilibrio con el todo" (Hegel, 2006, p. 558. Subrayados propios).

Si no es como resistencia, desde la forma presente de estos conceptos, el recurso a los orígenes no tiene fuerza vinculante suficiente en nuestro ahora, pues la identidad de una cosmo-polis no se ve amenazada si esos orígenes no existen o nos son desconocidos o indiferentes. A la identidad de un pueblo les son prescindibles sus 'antepasados', puede autofundarse y permanecer así en autoerotismo fundacional: le basta una geografía y un anhelo (¿cuál? El de ser en la continua tensión de los tiempos, el de la mala consciencia de la ausente lamentación). Y la oposición simple de tradición/progreso se soluciona no mediante la anulación de alguno de los componentes, sino en su articulación, en su equilibrio. Ella es la metro-polis: ya no tan grande, fluida y expandida, al punto de ser el mismo cosmos, pero ya determinando cosmológicamente todo particular; ya tampoco con la unitaria identidad de su historia cerrada, pero haciendo efectiva aun la presencia de una carne. Metraje multiplicado del pueblo, ampliación concéntrica y pausada, multiplicación bordeada por las sustracciones necesarias de la memoria. El pasado puede ubicarse por fin en su apropiado lugar en el nudo cronológico que le había sido negado ${ }^{12}$. La omnívora identidad

\footnotetext{
${ }^{12}$ Esta estructura de la Culpa acá identificada, no es solo adjudicable al movimiento de la temporalidad mencionado. A ella pertenecen los actuales procesos que gobiernan partes
} 
del capitalismo subsume en sí misma aquello que suponía presentarse como resistencia, como modificación de la forma misma del movimiento. Los ancestros solo tendrían lugar ya no como la mera identidad cerrada de sus prácticas y saberes, sino como aquello que detiene (momentáneamente) el desenfrenado movimiento capitalista y le brinda el lapso necesario de tiempo para que su actividad pueda retomarse con mayor fuerza en su rodeo (Agamben, 2011). La autoconfesión del capitalismo en la deixis de la memoria, le ha hecho posible la 'redención' de su culpa no a través de la automutilación de los santos, sino de la autopotenciación de su mismidad siempre latente y solo ahora hecha carne en comunión autorreferente $\Phi$

\section{REFERENCIAS}

Agamben, G. (2011). "Creación y salvación" . Giorgio Agamben. Desnudez. Buenos Aires: Adriana Hidalgo.

Bataille, G. (1992). El erotismo. Barcelona : Tusquets.

Benjamin, W. (2006). "El origen del 'Trauerspiel' alemán". Walter Benjamin. Obras, Libro I/vol. I. Madrid Abada .

Benjamin, W. (2008). El narrador. Santiago de Chile: Metales Pesados.

Benjamin, W. (2010). "Hacía la crítica de la violencia". Walter Benjamin. Obras, Libro II/vol. I. Madrid: Abada.

Caillois, R. (1959). L’homme et le sacré. París: Gallimard.

Devries, W.A. (2008). "Sense-certainty and the 'this-such'" en Moyar, D. y Quante, M. Hegel's Phenomenology of Spirit. Cambridge: Cambridge University Press.

Foucault, M. (2005). Historia de la sexualidad. V.1. La voluntad de saber. Madrid: Siglo XXI.

Franklin, B. (2004). "Advice to a Young Tradesman, Writen by an Old One". En Houston, A. Franklin, the autobiography and other writings on politics, economics, and virtue. Cambridge: Cambridge University Press.

importantes y diversas de la producción. Tanto la llamada responsabilidad social empresarial, como la producción amigable con el ambiente, hasta las emblemáticas políticas laborales de Google (que funcionan bajo la idea del ambiente más acogedor y menos opresivo para los trabajadores) que se presentan globalmente como las 'pausas activas' de los trabajadores, pueden ellas cargar en sí con esa Culpa (particular para cada esfera). Mi propósito acá era relacionar esa Culpa con cierto movimiento específico y plantear una matriz para su rastreo general. 
Han, B-C. (2012). La sociedad del cansancio. Barcelona: Herder.

Han, B-C. (2014). La agonía del eros. Barcelona: Herder.

Hegel, F.G.W. (2006). Fenomenología del espíritu. Valencia: Pre-textos.

Heidegger, M. (1996). Schelling y la libertad humana. Caracas: Monte Avila.

Heidegger, M. (2006). Ser y tiempo. Madrid: Trotta.

Houellebecq, M. (2009). Las partículas elementales. Barcelona: Anagrama.

Kierkegaard, S. (2004). Tratado de la desesperación. Buenos Aires: Leviatán.

Kristeva, J. (2006). Historias de amor. México D.F: Siglo XXI.

Lear, J. (1990). Love and its place in nature. New Haven: Yale University Press.

Michelet, J. (2014). La bruja. Un estudio de las supersticiones en la edad media. Madrid: Akal.

Rosenzweig, F. (1997). La estrella de la Redención. Salamanca: Sígueme.

Roudinesco, E. (2006). La familia en desorden. México D.F.: Fondo de Cultura Económica.

Roudinesco, E. (2009). Nuestro lado oscuro. Una historia de los perversos. Barcelona: Anagrama.

Sartre, J.P. (2009). El existencialismo es un humanismo. Barcelona: Edhasa.

Žižek, S. (2012). Less than nothing, Hegel and the shadow of dialectical materialism. Londres: Verso.

Zuleta, E. (1985). El pensamiento psicoanalítico. Medellín: Percepción. 